\title{
A REVIEW OF FIBER SYNERGY IN HYBRID FIBER REINFORCED CONCRETE
}

\author{
Niraj Kumar Singh ${ }^{\text {a }}$, Baboo Rai ${ }^{\text {a, }}$ * \\ a National Institute of Technology, Patna-800005, Bihar, India, e-mail: * baboo.rai@nitp.ac.in
}

Received: 04.09.2018 / Accepted: 12.09.2018/ Revised: 20.11.2018 / Available online: 15.12.2018

DOI: 10.2478/jaes-2018-0017

KEYWORDS: Hybrid Fiber, Fiber Synergy, Flexural Toughness, Permeability Resistance.

\begin{abstract}
Fibre reinforced concrete (FRC) presently utilized as a part of special structures subjected to dynamic loads for example airport pavements, expressways overlays, bridge decks and machine foundations. In most cases, FRC contains just a single kind of fibre. The utilization of at least two kinds of fibres in an appropriate mix can possibly improve the mechanical properties of concrete and result in performance synergy. The audit demonstrates that the blend of fibre allows a more powerful control of the dynamic crack development. This review analyses the components for synergistic impacts that gives direction on the fiber and matrix choice.
\end{abstract}

\section{INTRODUCTION}

Conventional concrete is comprised of cement, aggregates, water and with or without admixture and blending of every one of these materials gives a composite material. In most of the structure, concrete is used as major construction material. It is very good in compression but weak on tension. One vital constraint of conventional concrete, even of good quality, is the presence of micro-cracks, capillaries and micro-capillaries.

Concrete has a quasi-brittle failure; once failure is initiated the load carrying capacity is completely lost. The addition of steel fibres is a common practice used to improve concrete performance. Polypropylene fibre is a relatively new construction material and has been introduced to overcome some of the weak points of concrete, especially its low tensile strength, and the cracking that occurs either due to drying shrinkage, or plastic shrinkage. Post-peak ductility behaviour is enhanced by fibre in concrete. It also improves pre-crack fatigue and tensile strength and further eliminates temperature and shrinkage crack.

The term hybrid regularly alludes to composite mix and comprises of material with numerous properties. Use of more than one fibre helps to eliminate the deficiencies in concrete.

The concept of using one or more fibre in concrete is called hybridisation the combination of different material property are used to form a composite composition and generally termed as a hybrid. The hybrid composites in concrete improve the overall performance of concrete.

Hybrid fibre-reinforced concrete (HyFRC) is a category of FRC portrayed by its composition. It comprises no less than at least two sorts of fibres of various sizes, shapes or geneses. HyFRC is a composite material comprising of hydraulic cement, sand, coarse aggregate water and more than one type of fibres. Hybrid composite fibre concrete has wide applications as secondary reinforcement in recent years because of their property to resist microcracks. In case of Polypropylene fibre (PPF) and steel fibres optimization of mechanical and conductivity properties can be realized by amalgamating different types, kinds, and sizes of fibres.

A mixture of organic and inorganic fibres can be utilized in producing Cement-based composites which can show the benefits of both. The high impact strength resulting from nylon and polypropylene will allow stability for a long period of time when normally used. Enhanced performance in bending may be attainable with organic fibres by refining the transfer of stresses to the fibres by utilizing higher volume fractions (Walton \& Majumdar, 1975).

It has appeared in the past (Bentur \& Mindess, 2006; Mobasher \& Li, 1996; Guodong Xu \& Hannant, 1992) that by utilizing the possibility of hybridization with two particular fibers joined in a typical cement matrix, the hybrid composite can offer all the more engaging building

\footnotetext{
* Corresponding author: Baboo RAI, Associate professor, e-mail: baboo.rai@nitp.ac.in
} 
properties in light of the way that the proximity of one fiber empowers the more gainful utilization of the latent properties of the other fiber.

The hybrid composites envisaged by researchers (Bindiganavile \& Banthia, 2001; C. Qian \& Stroeven, 2000; C. X. Qian \& Stroeven, 2000) were primarily centred around cement paste or mortar. The mechanical properties of hybrid fibre- strengthened concrete at low fibre volume fraction have not been examined beforehand. During the early phase of this decade research into HyFRC has been fairly frequent. By using hybrid fibres in a concrete mixture the similar properties of concrete can be accomplished as those appeared by standard fibre fortified concrete but with a smaller amount of fibres addition.

\section{HYBRID FIBER SYNERGY}

"In well-designed hybrid composites, there is a positive interaction between the fibres and the resulting hybrid performance exceeds the sum of individual fibre performances". This phenomenon is often termed "Synergy" (Balaguru \& Shah, 1992; Bentur \& Mindess, 2006; G. Xu, Magnani, \& Hannant, 1998). Many fibre combinations may provide 'Synergy' with the most commonly recognized being:

$>$ Hybrids based on fibre constitutive response: One kind of fibre involved in the Hybrid improves the primary crack stress and ultimate strength as it is stronger and stiffer while the other fibre enhances the durability and strain limit in the post-cracking zone as it is more flexible and ductile

$>$ Hybrids based on fibre dimensions: one kind of fibre involved in Hybrid is smaller that controls the development of macro-cracks span while the other fibre is larger which can capture the spreading macrocracks for enhancing the durability of the composite.

$>$ Hybrids based on fibre function: One kind of fibre is proposed to enhance the fresh and early age properties, for example, the simplicity of creation and plastic shrinkage, while the second fibre leads to enhanced mechanical properties. In other words, hybrids based on distinctive durability properties. The strength and/or toughness retention properties with age are enhanced by the presence of the durable fibre.

\subsection{Researches on Fiber Synergy with Hybrids Based on Polypropylene Fiber}

Early researches in the past are based on the identification of the fibre combination that produced the maximum synergy. In one such study, (N. Banthia \& Sheng, 1990) combined/pooled carbon fibres with a low modulus of elasticity and steel fibres with a high modulus of elasticity. The prominent improvement was noticed because of the addition of steel fibres while enhanced toughness was noticed because of carbon fibre. In another study (Larsen \& Krenchel, 1991) steel and propylene fibre were added to the cementitious composite which led to increase in fracture energy by approximately $40 \%$ after 10 years of outdoor exposure. Increase in compressive strength due to hybridization of steel and polypropylene fibre is also reported (Mette \& Aarre, 1990).

In the mid-90's polypropylene fibre has attracted the most attention among researchers. This was mainly due to its low cost enhanced resistance to shrinkage cracking and outstanding toughness behaviour in concrete fortified with polypropylene fibre (Alhozaimy, Soroushian, \& Mirza, 1996).

Mechanical properties of concrete improve in a limited range when concrete is reinforced with a single type of fibre, on the contrary, superior properties are achieved in case of the FRC where concrete is reinforced with two or more types of fibres (Mobasher \& Li, 1996). The authors investigated the properties of concrete made with hybrids based on polypropylene fibre, carbon, and alumina.

The problem of crack propagation at different stages in concrete was well addressed in their work. Load versus crack mouth opening displacement (CMOD) response showed that there was $75 \%$ increase in peak load as compared to concrete containing only polypropylene fibres. The outcome of the result clearly showed that there is a beneficial interaction between the fibres which led to a better performance at HyFRC as compared to mono-fibre composites.

C.X. Qiana, P. Stroeven (2000) (C. X. Qian \& Stroeven, 2000) investigated the general properties of HyFRC under static loading. Two types of HyFRC were produced one in which steel fibres was pooled with polypropylene fibres and another in which small steel fibres were combined with larger one. Low fibre volume fraction was used with polypropylene fibre up to $0.3 \%$ and steel fibre volume up to $1.2 \%$. The study mainly dealt with a proper combination of fibre sizes and proper aggregate gradation with minimum cement content. The synergy effect showed significant improvement in case of hybrid fibre composites as compared to mono-fibre composites. Large improvement in compressive strength was reported with the addition of small steel fibre as compared to large steel fibre type.

Wu Yaoa, Jie Lib, Keru Wu (2001) (Yao, Li, \& Wu, 2003) studied three different types of hybrid composites using fibre combinations of polypropylene (PP) and carbon, carbon and steel, and steel and PP fibres at the same volume fraction $(0.5 \%)$. The performance of such concrete was evaluated in terms of compressive, splitting tensile and flexural properties. Test results showed superior composite performance in case of HyFRC as compared to their individual fibre-reinforced concretes. The test results indicated improved strength and enhanced toughness in case of hybrid fibres at low fibre volume fraction. The synergy effect of individual fibres showed high modulus and tensile strength in case of carbon fibre. Steel fibres showed medium elongation as compared to polypropylene fibre. 
Low modulus and tensile strength were reported for polypropylene fibre in comparison to steel and carbon fibre. Few other authors (Arisoy \& Wu, 2008; Johnston, 1974; Song \& Hwang, 2004) reported that the use of steelpolyvinyl alcohol (PVA) hybrid fibres can enhance the workability in concrete mixing and the material strength and deformability as well.

\section{SYNERGISTIC EFFECTS IN TERMS OF FLEXURAL TOUGHNESS}

There has been growing interest in HyFRC using two or more fibre types. Some of the authors (N. Banthia \& Sheng, 1990; Kobayashi \& Cho, 1982) performed experimental studies to investigate the behavioural characteristics of steel and carbon HyFRC and steel and polypropylene HyFRC, respectively. Their results showed that the use of HyFRC can enhance both material properties and structural capacities. The test results of few authors (Lawler, Zampini, \& Shah, 2002; Weiss \& Shah, 2002) contributed to quantify the crack damage (i.e. plastic shrinkage and restrained shrinkage cracking) and to use the hybrid fibre reinforcement for the purpose of cracking control of concrete structures.

The use of different fibre types with different fibre lengths can increase the tensile strength of concrete and is effective for crack control for both micro-cracks and macro-cracks (Lawler et al., 2002; Yao et al., 2003).

The increase in toughness and strain capacity in post crack zone with enhancement in ultimate strength due to hybridization of steel and polypropylene fibre has been also reported (Zheng \& Feldman, 1995). Similar findings have also been reported in the literature (Kim, Yi, \& Kim, 2001; C. Qian \& Stroeven, 2000).

Equivalent modulus and synergistic interaction between steel and carbon fibre resulted in highest strength and flexural toughness among the three hybrids composites (Table1) (Yao et al., 2003). The results of synergy as reported by the authors are presented in Table 2 and are shown graphically in Figure 1 and Figure 2.

Table 1. Properties of Carbon Steel and Polypropylene Fiber (Yao et al., 2003)

\begin{tabular}{lccc}
\hline & Carbon & Steel & PP \\
\hline Length $(\mathrm{mm})$ & 5 & 30 & 15 \\
Diameter $(\mu \mathrm{m})$ & 7 & 500 & 100 \\
Density $\left(\mathrm{g} / \mathrm{cm}^{3}\right)$ & 1.6 & 7.8 & 0.9 \\
Modulus $(\mathrm{GPa})$ & 240 & 200 & 8 \\
Elongation at break (\%) & 1.4 & 3.2 & 8.1 \\
Tensile strength (MPa) & 2500 & 1500 & 800 \\
\hline
\end{tabular}

Table 2. Mechanical Properties of FRC (Yao et al., 2003)

\begin{tabular}{|c|c|c|c|c|c|c|c|c|c|}
\hline \multirow[t]{2}{*}{$\begin{array}{l}\text { Batch } \\
\text { no. }\end{array}$} & \multicolumn{3}{|c|}{$\begin{array}{l}\text { Fiber volume } \\
\text { fraction }(\%)\end{array}$} & \multirow[t]{2}{*}{$\begin{array}{l}f_{\mathrm{c}}^{\prime} \\
(\mathrm{MPa})\end{array}$} & \multirow[t]{2}{*}{$\begin{array}{l}f_{\text {sp }}^{\prime} \\
(\mathrm{MPa})\end{array}$} & \multirow[t]{2}{*}{$\begin{array}{l}\text { MOR } \\
(\mathrm{MPa})\end{array}$} & \multicolumn{3}{|c|}{$\begin{array}{l}\text { Toughness } \\
\text { index }\end{array}$} \\
\hline & Carbon & Steel & PP & & & & $I_{5}$ & $I_{10}$ & $I_{30}$ \\
\hline 1 & - & - & - & & & & 3.16 & 5.89 & 9.78 \\
\hline 2 & 0.5 & - & - & 50.7 & 5.21 & 6.02 & 4.08 & 7.48 & 14.82 \\
\hline 3 & - & 0.5 & - & 47.8 & 4.80 & 6.90 & 4.15 & 7.90 & 22.80 \\
\hline 4 & - & - & 0.5 & 44.5 & 4.14 & 5.74 & 4.04 & 6.26 & 16.76 \\
\hline 5 & 0.2 & 0.3 & - & 58.2 & 5.95 & 7.36 & 4.23 & 8.14 & 29.32 \\
\hline 6 & 0.2 & - & 0.3 & 57.8 & 5.72 & 7.30 & 3.89 & 6.20 & 15.90 \\
\hline 7 & - & 0.2 & 0.3 & 45.3 & 4.46 & 5.83 & 3.40 & 6.31 & 18.44 \\
\hline
\end{tabular}

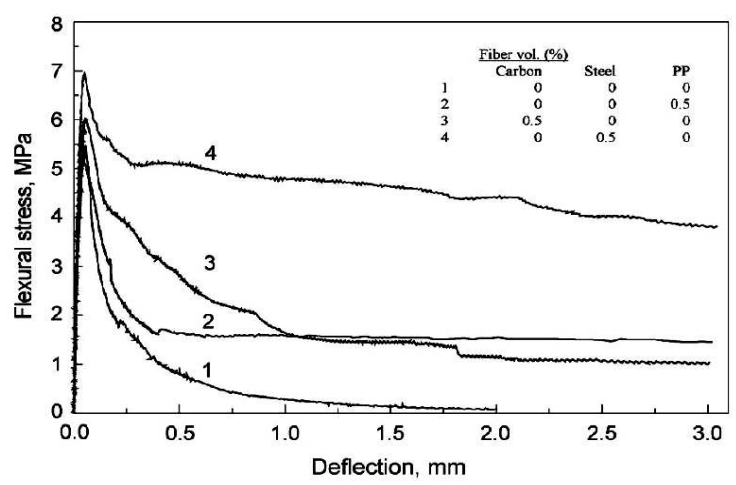

Figure 1. Flexural Strength versus Deflection for FRC Beams (Yao et al., 2003)

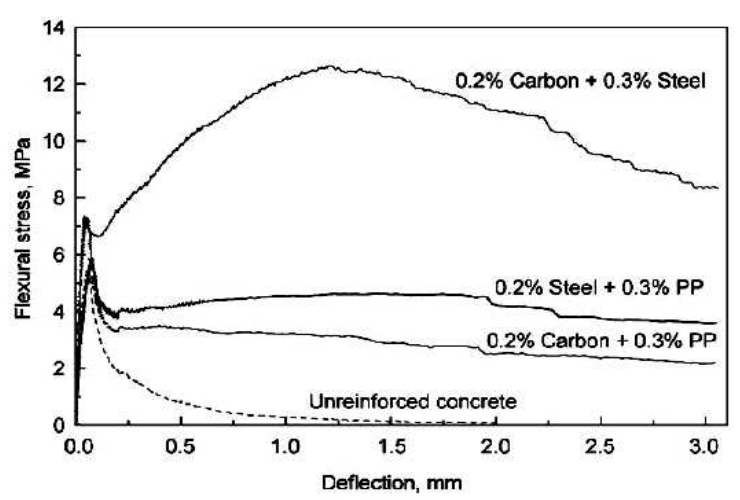

Figure 2. Flexural Strength versus Deflection for HyFRC

(Yao et al., 2003)

Hybridization of steel fibre and polypropylene fibre improves the resistance to both inception and engendering of cracks, and that such principal fracture tests are exceptionally helpful in developing high-performance hybrid fibre composites (N. Banthia \& Nandakumar, 2003). The presence of hybrid fibres in the concrete can resist tensile stress in the tensile zone below the neutral axis as it incorporates more destructive energy in the hybrid fibrereinforced concrete, as it has more amount of the fibre content in it. In another study ( $\mathrm{N}$ Banthia, Cangiano, Cucitore, Plizzari, \& Sorelli, 2003) studied the performance of hybrid micro and macro steel fibre under static and fatigue test. For this purpose, ten beams and cylinders were designed with the same concrete matrix in 
terms of cement content $\left(400 \mathrm{~kg} / \mathrm{m}^{3}\right)$, w/c ratio $(0.45)$ dose of superplasticizer and grain size of siliceous aggregates.

The results of static test demonstrated synergistic effects in terms of material toughness for HyFRC with a combination of different sizes of steel fibres. Increase in peak load form bending test and improved post crack strength for small crack openings was reported in case of microfibers. The results also showed more effective control of dynamic crack development. A few experimental results presented in the study are shown in Figure 3 and Figure 4 for specimens containing hybrid fibre.

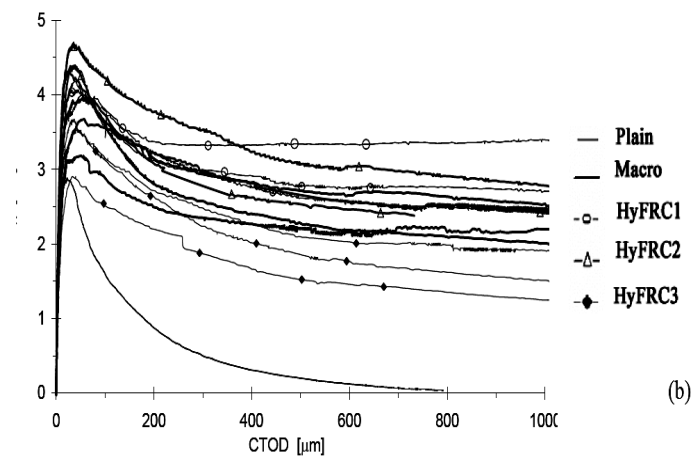

Figure 3. Typical Experimental Results from Static Tests on Specimens with Hybrid Fibres (Banthia et al., 2003)

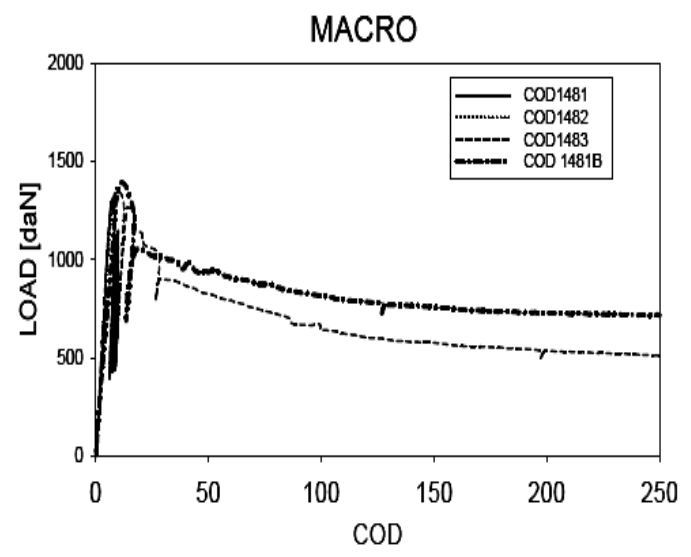

Figure 4. Typical Experimental Results from Cyclic Tests on Cylinders with Hybrid Fibres (Banthia et al., 2003)

In a similar type of study (N. Banthia \& Gupta, 2004; Nemkumar Banthia \& Soleimani, 2005), the fracture energy synergy effect on several types of hybrid fibres based on polypropylene pooled with mesophase carbon fibre and low modulus isotropic based carbon fibre pooled with high modulus mesophase based carbon fibre has been reported. Hybridization causes highest level of fracture energy synergy and strength has a major role to play in getting an optimized hybrid composite (N. Banthia \& Gupta, 2004; Nemkumar Banthia \& Soleimani, 2005; Yazici, 2008).

The synergistic effects in terms of first crack strength, failure strength and strength reliability of mono-fibre composites and hybrid fibre composites have been reported
(Song, Wu, Hwang, \& Sheu, 2005). The study revealed that Hybrid fibre composites showed larger scatter in percentage increase in the number of post crack blows as compared to mono-fibre composites. Statistical analysis showed improvement in reliabilities of first crack and failure strength in case of hybrid fibre reinforced concrete when compared to steel fibre reinforced concrete.

N. Banthia, M. Sappakittipakorn (N. Banthia \& Sappakittipakorn, 2007) hybridized large diameter crimped steel fibre with small diameter crimped steel fibre to investigate the toughness characteristics of such hybrid fibre composites. Workability and fibre dispensability was maintained in the fresh state. The results demonstrated that there was a significant improvement in toughness and hence concluding that such hybridization indeed is a promising concept in the future. The tests were performed in accordance with the ASTM C1018; the curves were evaluated as per the recommendations the Japan Society of Civil Engineers (JSCE SF4) procedure. The flexural toughness factor $(\sigma b)$ as per the JSCE method is given by:

$$
\sigma_{\mathrm{b}}=\frac{\tau_{\mathrm{b}}}{\delta_{\mathrm{tb}}} \times\left(\frac{L}{b \times h^{2}}\right)
$$

The test results are depicted in Table 3 and average flexural load-deflection curves for hybrid fibres at a low volume fraction of $0.75 \%$ are shown in Figure 5.

Table 3. Flexural Test Results (Banthia \& Sappakittipakorn, 2007)

\begin{tabular}{|c|c|c|c|c|c|c|c|}
\hline \multirow[t]{2}{*}{ Mix } & \multicolumn{3}{|c|}{ Crimped steel fiber (\%) } & \multirow{2}{*}{$\begin{array}{l}\text { Peak } \\
\text { load } \\
(\mathrm{kN})\end{array}$} & \multirow{2}{*}{$\begin{array}{l}\text { Deflection } \\
\text { at peak } \\
\text { load }(\mathrm{mm})\end{array}$} & \multirow{2}{*}{$\begin{array}{l}\text { Post- } \\
\text { crack } \\
\text { strength } \\
\text { at } L / m= \\
2 \mathrm{~mm} \\
(\mathrm{MPa})\end{array}$} & \multirow{2}{*}{$\begin{array}{l}\text { JSCE } \\
\text { flexural } \\
\text { toughness } \\
\text { at } \\
\delta=2 \mathrm{~mm} \\
\text { (MPa) }\end{array}$} \\
\hline & $0.80 \mathrm{~mm}$ & $0.45 \mathrm{~mm}$ & $0.40 \mathrm{~mm}$ & & & & \\
\hline 1 & 0.75 & & & 12.68 & 0.032 & 2.870 & 2.859 \\
\hline 2 & 0.50 & & & 12.67 & 0.034 & 2.719 & 2.710 \\
\hline 3 & & 0.75 & & 13.25 & 0.035 & 4.078 & 4.049 \\
\hline 4 & & 0.50 & & 13.04 & 0.033 & 3.284 & 3.265 \\
\hline 5 & 0.25 & 0.25 & & 10.70 & 0.033 & 2.494 & 2.486 \\
\hline 6 & 0.50 & 0.25 & & 11.88 & 0.031 & 3.103 & 3.086 \\
\hline 7 & & & 0.75 & 12.72 & 0.039 & 4.172 & 4.138 \\
\hline 8 & & & 0.50 & 12.87 & 0.032 & 2.939 & 2.926 \\
\hline 9 & 0.25 & & 0.25 & 11.96 & 0.034 & 2.866 & 2.851 \\
\hline 10 & 0.50 & & 0.25 & 10.85 & 0.034 & 3.558 & 3.532 \\
\hline 11 & 0.25 & 0.50 & & 12.67 & 0.033 & 3.537 & 3.513 \\
\hline 12 & 0.25 & & 0.50 & 11.89 & 0.040 & 3.295 & 3.274 \\
\hline
\end{tabular}




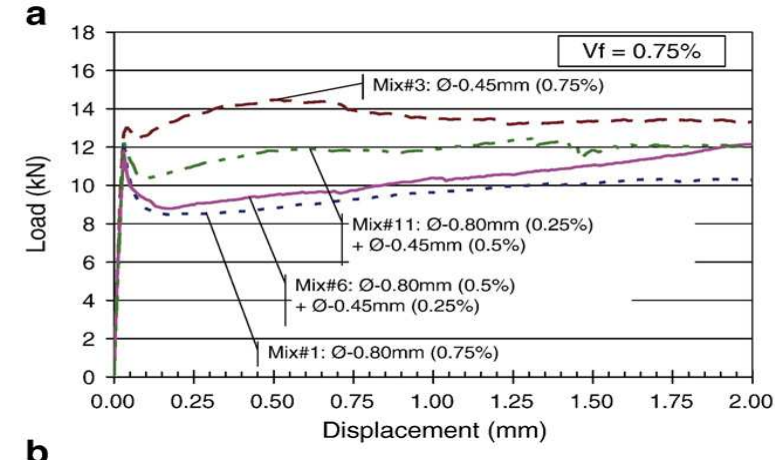

b

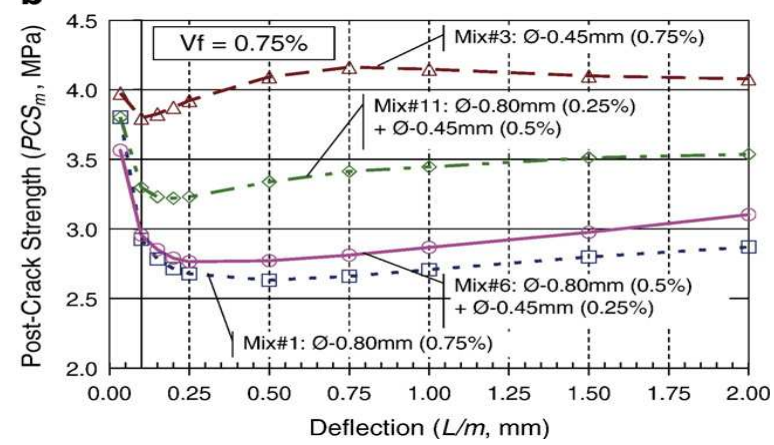

Figure 5. a. Average flexural load-deflection curves b. Post crack strength of the single and hybrid fibre

(Banthia \& Sappakittipakorn, 2007)

Skazlic et.al 2008 (Marijan Skazlić, 2009) in their study categorized FRC depending on the amount of fibres added to concrete. In one category fibre volume fraction in FRC is less than $2 \%$ and in another category fibre volume fraction is $\geq 2 \%$. The study progressed with an assumption that by addition of $30 \mathrm{~kg} / \mathrm{m}^{3}$ fibre in FRC the durability properties namely toughness, absorption energy, resistance to dynamic load improves. They outlined some basic results of the investigation in terms of the flexural behaviour of hybrid fibre reinforced concrete containing $30 \mathrm{~kg} / \mathrm{m}^{3}$ steel fibre. For these purpose 12 FRC mixtures with $16 \mathrm{~mm}$, aggregate size was prepared. Three types of steel fibres namely hooked end, sickle-shaped and wave-shaped were used with different fibre length and aspect ratio to prepare hybrid steel fibre.

The experimental findings demonstrated that hooked end steel fibre of $30 \mathrm{~mm}$ length and $60 \mathrm{~mm}$ length in a combination of $50 \%$ each gave the optimum synergetic effect. The synergistic effect in terms of flexural behaviour was graphically represented and is shown in Figure 6 and Figure 7. In their study, they established that hybrid steel fibre composites with different length result in enhanced concrete durability as compared to single long fibre reinforced concrete.

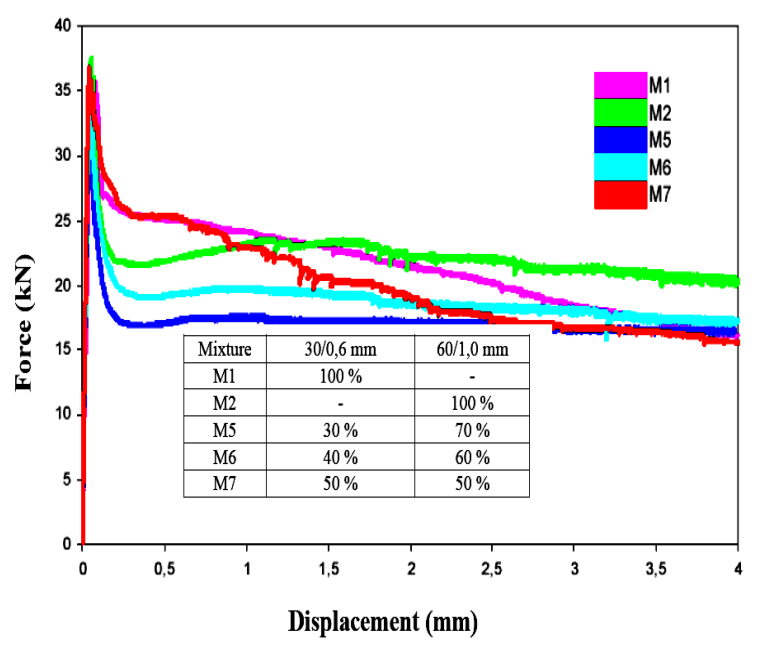

Figure 6. Flexural strength diagram

(Skazlić \& Bjegović, 2009)

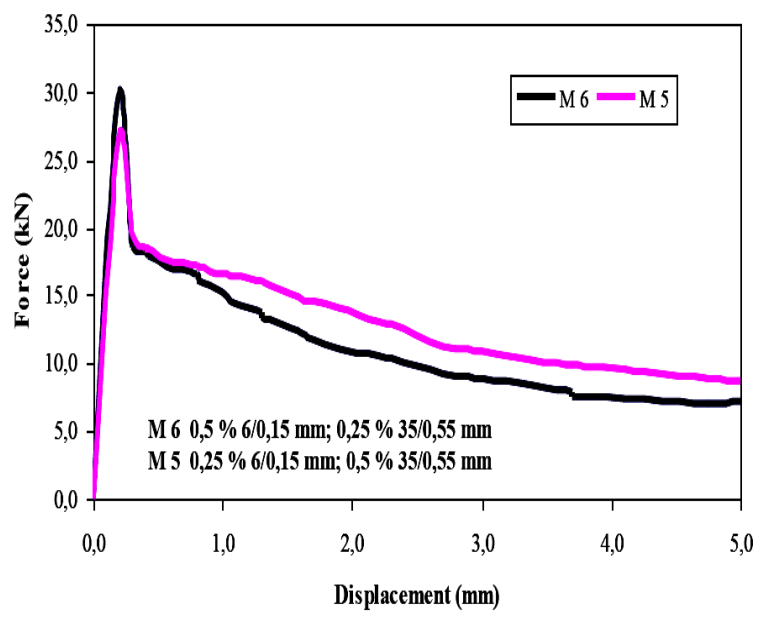

Figure 7. Flexural toughness diagrams for HyFRC

(Skazlić \& Bjegović, 2009)

Few authors (Plizzari, Cangiano, \& Alleruzzo, 1997; Slowik, Plizzari, \& Saouma, 1996) studied the fracture mechanism in concrete when subjected to cyclic loads. They observed that concrete damage mainly occurs in the micro- cracked zone which was termed a Fracture Process Zone (FPZ) (Figure 8). They also commented that if the presence of FPZ is taken into account beforehand then the behaviour of concrete structural elements subjected to lowcycle fatigue can be assessed correctly. 

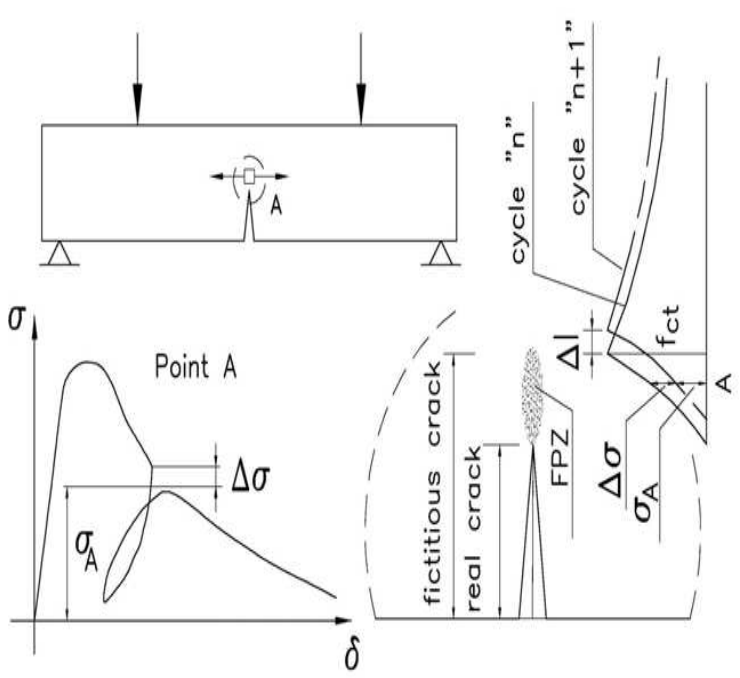

Figure 8. Stress Distribution along the Fracture Process Zone in Concrete Specimens under Cyclic Loading (Hillerborg, Modéer, \& Petersson, 1976)

Strength Modeling of $60 \mathrm{MPa}$ High-Strength Concrete (HSC) with Hybrid Fibre Reinforcement by combining steel and polyolefin fibre at different volume fraction has been reported (Ravichandran, Suguna, \& Ragunath, 2009). Comparison of the strength properties was done between high strength concrete without fibres with high strength concrete and hybrid fibre reinforced concrete. The experimental result presented in Table 4, demonstrated enhanced strength effectiveness in case of HSC with Hybrid Fibre Reinforcement and HyFRC as compared to HSC.

The result further indicated that modulus of rupture of all fibrous concrete was higher as compared to HSC. Better performance in terms of flexural toughness was observed in case of HyFRC as compared to another concrete composite.

\subsection{Synergistic Effects in Terms of Permeability Resistance}

Durability directly relates to permeability and shrinkage of concrete. If the ability of concrete to resist shrinkage and cracking is enhanced then impermeability can improve. Reinforcing concrete with mono-fiber is helpful in resisting shrinkage but the effect is limited. Hybrid fibres of various sizes and sorts may assume critical parts in resisting shrinkage and cracking at various scales to accomplish superior performance.

Sun et al. 2001 (Sun, Chen, Luo, \& Qian, 2001) investigated the effect of hybrid fibres and/or expansive agent on the shrinkage and water permeation properties of high-performance concrete and observed superior improvement for shrinkage resistance and impermeability of HPC than a mono amalgamation of hybrid fibres or expansive agent.

Table 4. Mechanical Properties of Fiber Reinforced Concrete (Ravichandran et al., 2009)

\begin{tabular}{|c|c|c|c|c|c|c|c|c|}
\hline \multicolumn{3}{|c|}{ Fibre volume $(\%)$} & \multicolumn{2}{|c|}{ Compressive strength (MPa) } & \multicolumn{2}{|c|}{ Splitting tensile strength (MPa) } & \multicolumn{2}{|c|}{ Modulus of nupture (MPa) } \\
\hline Steel & PO & Total & $\begin{array}{l}\text { Measured } \\
\text { value }\end{array}$ & $\begin{array}{l}\text { Strength } \\
\text { effectiveness }(\%)\end{array}$ & $\begin{array}{l}\text { Measured } \\
\text { value }\end{array}$ & $\begin{array}{l}\text { Strength } \\
\text { effectiveness }(\%)\end{array}$ & $\begin{array}{l}\text { Measured } \\
\text { value }\end{array}$ & $\begin{array}{l}\text { Strength } \\
\text { effectiveness (\%) }\end{array}$ \\
\hline$\overline{0.0}$ & 0.0 & 0.0 & 61.2 & 0.00 & 4.86 & 0.00 & 7.30 & 0.00 \\
\hline 0.5 & 0.0 & 0.5 & 63.5 & 3.76 & 7.67 & 57.82 & 9.60 & 31.51 \\
\hline 0.4 & 0.1 & 0.5 & 62.2 & 1.63 & 7.90 & 62.55 & 9.72 & 33.15 \\
\hline 0.3 & 0.2 & 0.5 & 61.6 & 0.65 & 7.39 & 52.06 & 9.35 & 28.08 \\
\hline 1.0 & 0.0 & 1.0 & 67.1 & 9.64 & 9.90 & 103.70 & 11.80 & 61.64 \\
\hline 0.8 & 0.2 & 1.0 & 66.3 & 8.33 & 10.00 & 105.76 & 12.00 & 64.38 \\
\hline 0.6 & 0.4 & 1.0 & 63.1 & 3.10 & 8.90 & 83.13 & 11.25 & 54.11 \\
\hline 1.5 & 0.0 & 1.5 & 69.9 & 14.20 & 11.26 & 131.69 & 12.89 & 76.58 \\
\hline 1.2 & 0.3 & 1.5 & 67.5 & 10.30 & 11.45 & 135.60 & 13.00 & 78.08 \\
\hline 0.9 & 0.6 & 1.5 & 65.2 & 6.54 & 10.80 & 122.22 & 12.54 & 71.78 \\
\hline 2.0 & 0.0 & 2.0 & 69.8 & 14.10 & 11.70 & 140.74 & 13.10 & 79.45 \\
\hline 1.6 & 0.4 & 2.0 & 69.2 & 13.10 & 12.50 & 157.20 & 13.80 & 89.04 \\
\hline 1.2 & 0.8 & 2.0 & 68.8 & 12.40 & 11.64 & 139.51 & 13.16 & 80.27 \\
\hline
\end{tabular}

Lawler et al. 2002 (Lawler et al., 2002) and Weiss and Shah (Weiss \& Shah, 2002) also performed extensive research to investigate the permeability and the cracking characteristics of hybrid fibre reinforced mortar. Similarly, 
the author (Lawler et al., 2002) demonstrated increased resistance to water penetration. Permeability test under tensile loading condition was conducted on the HyFRC specimens. In another study (Marijan Skazlić, 2009) investigated gas permeability and water absorption to evaluate the durability performance of the different hybrid fibre composites such as hooked-end steel fibres having aspect ratio: 64 and 45, straight steel fibres having aspect ratio 40 and fibrillated polypropylene fibres. Ten different concrete mixtures were prepared with w/c ratio of 0.41 and having equivalent workability in a fresh state. The low volume fraction of fibre composites ranging from $0.75 \%$ to $1.15 \%$ was used.

The study was based on the fact that the effect on certain properties of fresh and hardened fibres reinforced concrete made with steel fibres of different lengths are similar to that of concrete made with aggregates of different grain size. The results of the study demonstrated enhanced mechanical and durability performance in case of HyFRC hybridized with steel and polypropylene fibre than those as mono-fibre reinforced concrete. Further analysis of test results demonstrated that because of low modulus of elasticity PPF are effective in reducing crack propagation in Young concrete while hardened concrete behaviour gets enhanced due to addition steel fibre.

To know the absorption of water by capillary, Sorptivity test was carried out for durability study (Jayaprakasan \& Divya, 2015). Improvement in Compressive strength, Tensile strength and Flexural strength of HyFRC as compared to conventional concrete has been reported.

The impact strength of the HyFRC specimen directly depends on the percentage of fibre added to it. Number of blows for testing the impact strength of HyFRC increases with increase in percentage fibres added. Sorptivity was reported more as the percentage of fibres addition increases.

\subsection{Recent Researches on HyFRC}

When the composition of fibre hybrid composites is altered, it proportionally generates the synergetic effects. But some properties remain constant if the composition is altered irrespective of the fact that how many fibres are added for hybridization. In one study $(\mathrm{He}, \mathrm{Wu}, \& \mathrm{Jie}$, 2017) the mechanical properties of HyFRC hybridized with high elastic modulus and low elastic modulus fibres were investigated. Polypropylene fibre was used as low elastic modulus fibre whereas steel, basalt, polyvinyl alcohol fibres were incorporated as high elastic modulus fibre. The test outcome and investigation exhibit that solitary fibre and hybrid fibre will enhance the reliability of the concrete at failure. Brilliant mechanical properties of hybrid steel fibre-polypropylene fibre reinforced concrete are accounted for.

Improvement in modulus of rupture and toughness at $2 \%$ hooked end steel fibre volume fraction as compared to plain concrete in case of HyFRC has been reported in the literature (Eswari, Raghunath, \& Kothandaraman, 2011), the increase in above parameter was significant when compared to mono-fibre composite and plain concrete. Regression equations were developed to evaluate the strength and toughness of HyFRC. HyFRC was made with hooked end steel and polyolefin fibres.

A close agreement has been acquired between the predicted and experimental results. In another study (Hong \& Choi, 2012) a direct tension test was performed to investigate the nonlinear material behaviour of a HyFRC showing quasibrittle behaviour. Based on the experimental observations, a fictitious crack model, simulating a tensile stress-crackopening relationship, was developed. In the development of the crack model, the fracture mechanism of HyFRC and the effects of varying steel and carbon content in the HyFRC were addressed. The developed crack model was verified by comparing predictions with test results. For ease of application of the crack model in structure analysis and design, simplified equations for predicting and evaluating the tensile strength and fracture energy were developed. Positive hybrid effects of HyFRC has also been reported (Mei, $\mathrm{Xu}, \mathrm{Li}, \& \mathrm{Chi}, 2012$ ) when steel fibre volume ratio was less than $1 \%$ and polypropylene fibre volume was less than $0.1 \%$.

The results of the synergetic effect in term of $1^{\text {st }}$ crack load, flexural strength, flexural rigidity was evaluated (Jadhav \& Koli, 2013) the test result showed Significant improvement in flexural performance of HyFRC when steel and polypropylene fibre where hybridized. In a similar type of study (Selina Ruby, Geethanjali, Varghese, \& Priya, 2014) used crimped steel and polypropylene fibre with the ratio $\mathrm{S} 0.25+\mathrm{P} 0.75, \mathrm{~S} 0.5+\mathrm{P} 0.5$, S0.75+P0.25, (p-polypropylene, $\mathrm{S}$-steel) for M40 concrete. The strength test results demonstrated improvement in strength effectiveness as compared to plain concrete. It was reported that fibres limit the initiation and propagation of cracks in the microstructure of concrete under axial load.

Increase in peak tensile strength due to steel fibre while the increase in residual strength post-peak response due to polypropylene fibre has been reported in one study (L. Xu, Huang, Chi, \& Mei, 2016).

Variables used in the study were different fibre volume fraction and aspect ratio. Furthermore, improvement in the range between $20 \%$ and $80 \%$ in the case of tensile strength was observed in comparison to that of plain concrete. A predictive equation for shear strain relation and tensile strength was developed. The authors also proposed a simple elliptical cap model in the tension region which represented three-dimensional strength criterions for predicting multi-axial stress in tension region of HyFRC.

High strength concrete designed with proportions based on a percentage of $0 \%, 75 \%$ steel fibre hybridized with $25 \%$ PPF, 75\% steel fibre and 25\% PPF for fibre volume fraction of $1.5 \%$ demonstrated improved structural stiffness in case of HyFRC beam as compared to others (Amizah, Jusoh, Ibrahim, Rahman, \& Sam, 2017).

The best performance for flexural capacity was obtained in case of HyFRC beam. The bridging action of steel fibres retarded the crack propagation due to higher elastic 
modulus and tensile strength. The hooked end of steel fibre delayed the growth of macrocrack while PPF arrested the microcrack propagation due to the low elastic modulus.

As of late synergetic effects have been accounted for a wide assortment of properties, running from tensile strength (Jayaprakasan \& Divya, 2015; Wisnom et al., 2016), flexural strength (Dong, Sudarisman, \& Davies, 2013; Jayaprakasan \& Divya, 2015), impact resistance (Swolfs, Geboes, Gorbatikh, \& Pinho, 2017), fatigue (Shan \& Liao, 2002; Wu, Wang, Iwashita, Sasaki, \& Hamaguchi, 2010). Excellent resistance to air blast loading for hybrid fibre composite as compared to normal reinforced concrete is also reported (Yusof et al., 2013). In this study plastic, explosive P-E4 was used to air blast the concrete panel made of hybrid steel fibres. Parameters measured were blast load and mode of failure under static loading. Furthermore, there is very limited research available with regard to durability properties like electrical resistivity and water absorption of fibre reinforced concrete. Recent studies on electrical resistivity and water absorption report contradictory results. One of the studies (Afroughsabet \& Ozbakkaloglu, 2015) revealed that, with the incorporation of fibres, the result of electrical resistivity and water absorption test showed reducing trend as compared to plain concrete.

\section{CONCLUDING REMARKS}

On review of the researches, the advantages of using steel and polypropylene fibre in the concrete matrix can be summarised as there is a significant impact on the properties of hybrid reinforced concrete. A fibre having high durability increases toughness while fibre with low durability enhances the short-term performance of concrete. Further fibre which is flexible and ductile develop toughness and strain in post cracking zone which stronger and stiff enhances the stresses at first crack and also enhances the ultimate strength. Moreover, fibres which are small in size arrest the microcracks whereas fibre with large size helps in arresting the macrocracks. Together they help in controlling the propagation of micro and macrocracks. The hybrid composite in concrete improves the overall performance of concrete.

Fibre-hybridisation offers an inimitable prospect to mitigate some of the negatives of one fibre type by adding a second fibre type. Hybrid fibre reinforcement of concrete composites is quickly rising as an imaginative and promising method for enhancing the mechanical performance and durability of cement-based materials. While hybrid fibre reinforced cement composites are promising yet at the same time, there is significantly further research expected to build up the science and justification important for their enhancement.

\section{References}

Afroughsabet, V., \& Ozbakkaloglu, T. (2015). "Mechanical and durability properties of high-strength concrete containing steel and polypropylene fibers." Construction and Building Materials, 94, 73-82.

Alhozaimy, A. M., Soroushian, P., \& Mirza, F. (1996). "Mechanical properties of polypropylene fiber reinforced concrete and the effects of pozzolanic materials." Cement and Concrete Composites, 18(2), 85-92.

Amizah, W., Jusoh, W., Ibrahim, I. S., Rahman, A., \& Sam, M. (2017). "Flexural Behaviour of Reinforced Concrete Beams With Discrete Steel - Polypropylene Fibres." MATEC Web of Conferences, 01020.

Arisoy, B., \& Wu, H.-C. (2008). "Material characteristics of high performance lightweight concrete reinforced with PVA." Construction and Building Materials, 22(4), 635645.

Balaguru, P. N., \& Shah, S. P. (1992). Fiber Reinforced Cement Composites. McGraw-Hill; First Edition edition.

Banthia, N., Cangiano, S., Cucitore, R., Plizzari, G. A., \& Sorelli, L. (2003). "Hybrid Fibre Reinforced Concrete under Fatigue Loading." International Conference on FATIGUE CRACK PATHS (FCP 2003), Parma (Italy), 18 - 20 September, 2003, (Fcp), 18-20.

Banthia, N., \& Gupta, R. (2004). "Hybrid fiber reinforced concrete (HyFRC): Fiber synergy in high strength matrices." Materials and Structures/Materiaux et Constructions, 37(274), 707-716.

Banthia, N., \& Nandakumar, N. (2003). "Crack growth resistance of hybrid fiber reinforced cement composites." Cement and Concrete Composites, 25(1), 3-9.

Banthia, N., \& Sappakittipakorn, M. (2007). "Toughness enhancement in steel fiber reinforced concrete through fiber hybridization." Cement and Concrete Research, 37(9), 1366-1372.

Banthia, N., \& Sheng, J. (1990). "Micro-reinforced cementitious materials." In Materials Research Society Fall Meeting Proceedings (pp. 25-32).

Banthia, N., \& Soleimani, S. M. (2005). "Flexural response of hybrid fiber-reinforced cementitious composites." $A C I$ Materials Journal, 102(6), 382-389.

Bentur, A., \& Mindess, S. (2006). Fiber Reinforced Cementitious Composites. Civil Engineering.

Bindiganavile, V., \& Banthia, N. (2001). "Polymer and steel fiber-reinforced cementitious composites under impact loading - Part 1: Bond-slip response." ACI Materials Journal, 98(1), 10-16.

Dong, C., Sudarisman, \& Davies, I. J. (2013). "Flexural properties of e glass and TR50S carbon fiber reinforced epoxy hybrid composites." Journal of Materials Engineering and Performance, 22(1), 41-49.

Eswari, S., Raghunath, P. N., \& Kothandaraman, S. (2011). "Regression modeling for strength and toughness evaluation of hybrid fibre reinforced concrete." ARPN Journal of Engineering and Applied Sciences, 6(5). 
He, D., Wu, M., \& Jie, P. (2017). "Study on Mechanical Properties of Hybrid Fiber Reinforced Concrete." IOP Conf. Series: Earth and Environmental Science, 73(1).

Hillerborg, A., Modéer, M., \& Petersson, P. E. (1976). "Analysis of crack formation and crack growth in concrete by means of fracture mechanics and finite elements." Cement and Concrete Research, 6(6), 773-781.

Hong, S. G., \& Choi, K. K. (2012). "Crack modeling of steel-carbon hybrid FRCCs." Advanced Composite Materials, 21(4), 283-298.

Jadhav, H. S., \& Koli, M. D. (2013). "Flexural Behavior of Hybrid Fiber Reinforced Concrete Beams." International Journal of Structural and Civil Engineering Research, 2(3), 210-218.

Jayaprakasan, V., \& Divya, R. (2015). "Comparative study of hybrid fiber reinforced concrete and find optimum dosage of fiber." Int J Appl Civil Environ Eng, 16-23.

Johnston, C. (1974). "Steel fibre reinforced mortar and concrete - a review of mechanical properties." Fiber Reinforced Concr. SP-44, ACI, 127-142.

Kim, J. K., Yi, S. T., \& Kim, J. H. J. (2001). "Effect of specimen sizes on flexural compressive strength of concrete.” ACI Structural Journal, 98(3), 416-424.

Kobayashi, K., \& Cho, R. (1982). "Flexural characteristics of steel fiber and polypropylene fiber hybrid reinforced concrete." Composites, 13, 164-168.

Larsen, E. T., \& Krenchel, H. (1991). "Durability of FRCMaterials. In: Sidney Mindess and Jan Skalny." In Fiberreinforced Cementitious Materials: Symposium, Boston, Massachusetts, 1990, Materials Research Society Symposia Proceedings Vol. 211, Materials Research Society, Pittsburgh (pp. 119-124).

Lawler, J. S., Zampini, D., \& Shah, S. P. (2002). "Permeability of cracked hybrid fiber-reinforced mortar under load." ACI Materials Journal, 99(4), 379-385.

Mei, G. D., Xu, L. H., Li, S., \& Chi, Y. (2012). "Hybrid Effects on Strength of Steel-Polypropylene Hybrid Fiber Reinforced Concrete under Uniaxial and Triaxial Compression." Applied Mechanics and Materials, 268270, 782-787.

Mette, G., \& Aarre, T. (1990). "High-Strength Concrete with Increased Fracture-Toughness." Symposium $O$ Fiber-Reinforced Cementitious Materials, 39.

Mobasher, B., \& Li, C. Y. (1996). "Mechanical properties of hybrid cement-based composites." ACI Materials Journal, 93(3), 284-292.

Plizzari, G. A., Cangiano, S., \& Alleruzzo, S. (1997). "The fatigue behaviour of cracked concrete." Fatigue and Fracture of Engineering Materials and Structures, 20(8), 1195-1206.

Qian, C., \& Stroeven, P. (2000). "Fracture properties of concrete reinforced with steel - polypropylene hybrid fibres." Cement and Concrete Composites, 22, 343-351.
Qian, C. X., \& Stroeven, P. (2000). "Development of hybrid polypropylene-steel fibre-reinforced concrete." Cement and Concrete Research, 30(1), 63-69.

Ravichandran, A., Suguna, K., \& Ragunath, P. N. (2009). "Strength modeling of high-strength concrete with hybrid fibre reinforcement." American Journal of Applied Sciences, 6(2), 219-223.

Selina Ruby, G., Geethanjali, C., Varghese, J., \& Priya, P. M. (2014). "Influence of hybrid fibre reinforced concrete." International Journal of Advanced Structures and Geotechnical Engineering.

Shan, Y., \& Liao, K. (2002). "Environmental fatigue behavior and life prediction of unidirectional glasscarbon/epoxy hybrid composites." International Journal of Fatigue, 24(8), 847-859.

Skazlić, M. (2009). "Utilization of high performance fiberreinforced micro-concrete as a repair material." Civil Engineering, 859-862.

Skazlić, M., \& Bjegović, D. (2009). "Toughness testing of ultra high performance fibre reinforced concrete." Materials and Structures/Materiaux et Constructions, 42(8), 1025-1038. Retrieved from http://www.scopus.com/inward/record.url?eid=2-s2.068849097946\&partnerID $=40 \& \mathrm{md} 5=684 \mathrm{a} 9 \mathrm{a} 2435 \mathrm{e} 0 \mathrm{~d} 76878$ f8373a5526600e

Slowik, V., Plizzari, G. A., \& Saouma, V. E. (1996). "Fracture of concrete under variable amplitude fatigue loading." ACI Materials Journal, 93(3).

Song, P. S., \& Hwang, S. (2004). "Mechanical properties of high-strength steel fiber-reinforced concrete." Construction and Building Materials, 18(9), 669-673.

Song, P. S., Wu, J. C., Hwang, S., \& Sheu, B. C. (2005). "Statistical analysis of impact strength and strength reliability of steel-polypropylene hybrid fiber-reinforced concrete." Construction and Building Materials, 19(1), 19.

Sun, W., Chen, H., Luo, X., \& Qian, H. (2001). "The effect of hybrid fibers and expansive agent on the shrinkage and permeability of high-performance concrete." Cement and Concrete Research, 31(4), 595-601.

Swolfs, Y., Geboes, Y., Gorbatikh, L., \& Pinho, S. T. (2017). "The importance of translaminar fracture toughness for the penetration impact behaviour of woven carbon/glass hybrid composites." Composites Part A: Applied Science and Manufacturing, 103, 1-8.

Walton, P. L., \& Majumdar, a. J. (1975). "Cement-based composites with mixtures of different types of fibres." Composites, 6(5), 209-216.

Weiss, W., \& Shah, S. (2002). "Restrained shrinkage cracking: the role of shrinkage reducing admixtures and specimen geometry." Materials and Structures, 35(March), 85-91.

Wisnom, M. R., Czél, G., Swolfs, Y., Jalalvand, M., 
Gorbatikh, L., \& Verpoest, I. (2016). "Hybrid effects in thin ply carbon/glass unidirectional laminates: Accurate experimental determination and prediction." Composites Part A: Applied Science and Manufacturing, 88, 131-139.

Wu, Z., Wang, X., Iwashita, K., Sasaki, T., \& Hamaguchi, Y. (2010). "Tensile fatigue behaviour of FRP and hybrid FRP sheets." Composites Part B: Engineering, 41(5), 396402.

Xu, G., \& Hannant, D. J. (1992). "Flexural behaviour of combined polypropylene network and glass fibre reinforced cement." Cement and Concrete Composites, 14(1), 51-61.

Xu, G., Magnani, S., \& Hannant, D. J. (1998). "Durability of hybrid polypropylene-glass fibre cement corrugated sheets." Cement and Concrete Composites, 20(1), 79-84.

Xu, L., Huang, L., Chi, Y., \& Mei, G. (2016). "Tensile behavior of steel-polypropylene hybrid fiber-reinforced concrete." ACI Materials Journal, 113(2), 219-229.

Yao, W., Li, J., \& Wu, K. (2003). "Mechanical properties of hybrid fiber-reinforced concrete at low fiber volume fraction." Cement and Concrete Research, 33(1), 27-30.

Yazici, H. (2008). "The effect of silica fume and highvolume Class $\mathrm{C}$ fly ash on mechanical properties, chloride penetration and freeze-thaw resistance of self-compacting concrete." Construction and Building Materials, 22(4), 456-462.

Yusof, M. A., Mohamad Nor, N., Ismail, A., Choy Peng, N., Mohd Sohaimi, R., \& Yahya, M. A. (2013). "Performance of hybrid steel fibers reinforced concrete subjected to air blast loading." Advances in Materials Science and Engineering, 2013(14), 7 pages.

Zheng, Z., \& Feldman, D. (1995). "Synthetic fibrereinforced concrete." Progress in Polymer Science. 